\title{
TRANSFORMATIONAL LEADERSHIP VERSUS SHARED LEADERSHIP FOR TEAM EFFECTIVENESS
}

\author{
Thi Bich Hanh Tran ${ }^{*}$ and Anh Dung Vu ${ }^{2}$

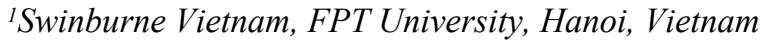 \\ ${ }^{2}$ Faculty of Arts and Sciences, College of Business and Management, \\ VinUniversity, Vinhomes Ocean Park, Gia Lam District, Hanoi, Vietnam \\ *Corresponding author: hanhttb2@fpt.edu.vn or hanhttb2@fe.edu.vn
}

Published online: 1 December 2021

To cite this article: Tran, T. B. H., \& Vu, A. D. (2021). Transformational leadership versus shared leadership for team effectiveness. Asian Academy of Management Journal, 26(2), 143-171. https://doi.org/10.21315/aamj2021.26.2.7

To link to this article: https://doi.org/10.21315/aamj2021.26.2.7

\begin{abstract}
This study aims at investigating the effect of transformational leadership and shared leadership on dimensions of team effectiveness and the mediating role of teamwork orientation. The data were collected from members of working teams in companies of different fields in Vietnam. The results show that both transformational leadership and shared leadership are significantly associated to team effectiveness including team performance, quality of team experience, and team viability. The effects of transformational leadership are more robust compared to those of shared leadership while both leadership styles are dramatically relevant to team viability. In addition, teamwork orientation serves as a significant partial mediator in the relationship between transformational leadership, shared leadership, and dimensions of team effectiveness. The study is an early research in evaluating the effect of transformational leadership and shared leadership on three dimensions of team effectiveness, namely team performance, quality of team experience, and team viability. It is also the very first to explore the mediating role of teamwork orientation in the effect of leadership approaches on components of team effectiveness. The study offers interesting empirical evidence of an under-researched Asian emerging economy - Vietnam - so providing practical implications for companies in Vietnamese context in particular and similar Asian economies.
\end{abstract}

Keywords: transformational leadership, shared leadership, teamwork orientation, team performance, quality of team experience, team viability

(C) Asian Academy of Management and Penerbit Universiti Sains Malaysia, 2021. This work is licensed under the terms of the Creative Commons Attribution (CC BY) (http://creativecommons. org/licenses/by/4.0/). 


\section{INTRODUCTION}

Leadership has been stressed as an influential factor to catalyse a variety of dimensions of team effectiveness like team performance and team member positive behaviours. Results from prior studies showed that leadership approaches lead to positive team consequences in general, but different leadership approaches affect target team outcomes with different magnitudes. Transactional leadership, transformational leadership, charismatic leadership, ethical leadership, and authentic leadership are the most commonly studied while the major studies in this ground examined the effect of a specific leadership approach or style on outcomes. Meanwhile, few studies have compared effects of two leadership styles or approaches on team outcomes. Recently, much scholarly attention has been paid to transformational leadership and shared leadership as the two typical approaches of leadership: vertical leadership and horizontal leadership, respectively. However, most of the studies comparing these two approaches are conceptual research (Kozlowski et al., 2016) while empirical study is quite limited with the only attempt of Choi et al. (2016) on Korean sample. Concretely, Choi et al. (2016) investigated the relationship between these two leadership approaches and team effectiveness and yielded the finding that each of the leadership approaches results in different team outcomes. Interestingly, various studies showed inconsistent predictions for effectiveness of each leadership approach. To exemplify, Feng et al. (2016) stressed transformational leadership to be superior than other approaches for team innovative behaviours while Fransen et al. (2018) considered shared leadership to be a more powerful predictor for team effectiveness than vertical leadership (i.e., transformational leadership). As the study by Choi et al. (2016) is the only welcome example comparing the two approaches with a single sample, more empirical evidence is needed to verify the discrepancies in the effects of the two approaches, particularly on other categories of outcomes. Meanwhile, according to Aubé and Rousseau (2005), team performance, quality of team experience, and team viability are the three most crucial aspects for team survival and prosperity. Grounding on these studies, the present study attempts to evaluate the differences in the effects of transformational leadership and shared leadership on team performance, quality of team experience, and team viability.

Given the expected influence of transformational leadership and shared leadership on team effectiveness, the study garners an interest in the mechanisms for the effect as to date the number of studies exploring this is quite scanty. No studies have been captured about the common mechanism between the two leadership approaches and team effectiveness. This lacuna in research should be addressed because learning about influential mechanisms helps firms to properly attend to 
the practices for fostering team effectiveness. Teamwork orientation can be a potential mediator because teamwork orientation has been proved to be conducive to positive team-related outcomes (Mohammed \& Angell, 2004; Shamir, 1990; Wagner, 1995; Wang et al., 2014). In the meantime, prior studies also proved that leadership is influential to teamwork orientation among team members (Podsakoff et al., 1990). Regrettably, no studies, to date, have evaluated teamwork orientation as a mediating variable between transformational leadership, shared leadership, and team effectiveness.

In addition, GLOBE study (Wolf, 2006) showed that in different environments like countries, leadership approaches may be variously viable and effective. This necessitates empirical studies of leadership approaches in different contexts. Vietnam is an interesting context for comparing transformational leadership and shared leadership for two main reasons. First, in accordance with GLOBE study, the country group of China, Korea, and Taiwan has a shared leadership while Vietnamese culture is the closest to this group's culture. Therefore, shared leadership is expected to be viably present in Vietnamese context. Transformational leadership is also expected to be present strongly in Vietnam because transformational leadership is deemed more viable and effective in collective culture compared to individual culture, while Vietnam is a collective culture. Second, operating in an emerging economy with numerous unexpected changes, companies in Vietnam need effective leadership approaches for achieving various outcomes, necessarily inclusive of team consequences. Comparing effectiveness of transformational leadership and shared leadership in Vietnam is a timely response to the need of Vietnamese firms. Though sharing several common characteristics with Asian countries including China, Japan, South Korea, and Taiwan like Confucian spirit, a culture of collectivism and high-power distance (Park et al., 2018; Choi et al., 2017), Vietnam still possesses different social and historical backgrounds that can shape certain variations in preferences of leadership approaches in organisations. Hence, study of Vietnamese context is worthwhile.

This study aims at investigating the influence of transformational leadership and shared leadership on three types of team effectiveness including team performance, quality of team experience, and team viability. The second aim of the study is to examine the mediating role of teamwork orientation in the effect. Its third purpose is that with the findings, the study offers valuable managerial implications for organisations to catalyse better team effectiveness. 


\section{LITERATURE REVIEW}

\section{Transformational Leadership}

Transformational leadership has been found to dominate the literature (Day, 2012). Transformational leadership refers to leader behaviours in helping followers to meet expected goals by promoting changes in accordance with their values and interests. A transformational leader is considered to have four characteristics: idealised influence, inspirational motivation, intellectual stimulation, and individual consideration (Braun et al., 2013). Idealised influence connotes leader's behaviours that instill in followers' pride and respect for being with transformational leader. Inspirational motivation entails leader behaviour of creating motivations for followers by enhancing their vision at both personal and organisational levels. Inspirational motivation is expressed when leaders have a clear vision of the future, set out goals, and have confidence for achieving those set goals. Intellectual stimulation indicates leader behaviour for encouraging followers' unstereotyped thinking styles and new perspectives for achieving goals or solving problems. Leader's intellectual stimulation is perceived when leader promotes followers' progress by questioning hypotheses and having access to old matters in different manners. Individual consideration refers to leader's treatment of followers as an individual with distinct characteristics, rather than a common team member, and leader's recognition of followers' individual needs, capabilities, and desires. Prior studies have revealed that followers will provide responses to leader's positive behaviours (Mesu et al., 2015), and leader's effects on followers' behaviours and psychology are larger in small enterprises compared to high enterprises because of closer relationships and more frequent interactions (Koch \& Van Straten, 1997).

\section{Shared Leadership}

Shared leadership refers to "the process of influencing others to understand and agree about what needs to be done and how it can be done effectively, and the process of facilitating individual and collective efforts to accomplish shared objectives" (Yukl, 2002, p. 7). The degree of sharing in leadership can be expressed through many formats such as when leaders and followers share responsibilities for achieving collective goals, together taking the leader positions like the case of William Hewlett and David Packard co-founding and leading HP, or when members take turns for a leader position (Hackman \& Johnson, 2013). When leadership is shared, common characteristics perceived among team members are cooperative leadership, collective decision making, and good leader-follower relationships. 
Research has proved the significant influence of shared leadership on team performance (Carson et al., 2007; Erkutlu, 2012), process-related outcomes, and team atmosphere (Choi et al., 2017; Hoch, 2013). Fransen et al. (2018) stressed the significance of shared leadership such that it associates with social-related function that develops a positive climate, solve interpersonal problems, satisfy needs of team members, and foster cohesion among team members. Pearce and Conger (2003) even reckoned that shared leadership is the best leadership approach as it enables members to have more autonomy in their duties and motivate them to make efforts in achieving organisational goals. Contractor et al. (2012) also pointed out that as there exists pervasive presence of flatter organisational structures and empowered teams, the importance of shared leadership within teams is more emphasised. To the present, a majority of shared leadership studies are conceptual papers while empirical research of the concept is rather scanty.

\section{Team Effectiveness}

Prior research has well documented the impacts of leadership styles on team effectiveness (Burke et al., 2006; Carson et al., 2007; Choi et al., 2017). Studies have proposed different conceptualisations and measures of team effectiveness. To be precise, a group of studies treated team effectiveness with two dimensions: output effectiveness, and organising and planning effectiveness (Choi et al., 2017; Pearce \& Sims, 2002). As such, these studies focused on both output-related and process-related performance of teams. Contrary to this, some studies proposed a variety of factors for team effectiveness such as performances in work quality, in changes, in interpersonal interactions, in values, and overall performance. This conceptualisation suggests that there are various aspects in measuring team effectiveness, and an evaluation of specific aspects of team effectiveness will provide an insight into team effectiveness. Remarkably, according to Aubé and Rousseau (2005), team effectiveness is measured with team performance, quality of team experience, and team viability. These three distinct aspects are deemed crucial for team survival and prosperity. In the emerging economies with a high level of pressures in work, including team work and a variety of changes, evaluation of team effectiveness through these three dimensions is suitable. Hence, the present study concentrates on three significant factors of team effectiveness: team performance, quality of team experience, and team viability. Team performance refers to team goal achievement, team work quality, and team productivity. Quality of team experience connotes quality of social environment in teams. Team viability entails team adaptability to changes, solving problems, accepting new members, and working together in the future. 


\section{Teamwork Orientation}

Teamwork orientation refers to the extent to which members have a positive attitude towards working in a team (Fransen et al., 2011; Mathieu et al., 2008). To state differently, teamwork orientation entails members' willingness to work with others in a cooperative manner and commitment to group goals and interpersonal relationships (Watson et al., 1998). Studies have proved that teamwork orientation is a significant determinant of individual satisfaction (Campion et al., 1993), personal learning (Mustafa et al., 2017; Williams et al., 2006), performance within a team (Mohammed \& Angell, 2004; Shamir, 1990; Wagner, 1995), team member exchange (Wang et al., 2014), and propensity to participate in teamwork and cooperate with other members (Eby \& Dobbins, 1997). Concerning antecedents, prior studies have identified cultural values including collectivism (Earley \& Gibson, 1998; Mustafa et al., 2017; Wagner, 1995) and power distance, uncertainty avoidance, and masculinity-femininity (Mustafa et al., 2017) as crucial factors affecting teamwork orientation of team members.

\section{RESEARCH MODEL AND HYPOTHESES DEVELOPMENT}

\section{Transformational Leadership and Team Effectiveness}

Empirical evidence from prior research purported that transformational leader's consideration of followers as individuals with different needs and characteristics makes them feel respected, and therefore motivating them to engage in positive conducts towards leaders or companies, including higher work performance (Choi et al., 2017). Moreover, transformational leader shares personal and organisational moral values with followers, and therefore enhancing their intrinsic motivation. The followers with high intrinsic motivation often regard team as a notable unit and so are more likely to make efforts for achieving collective goals. Chun et al. (2016) disclosed that transformational leadership fosters team performances as well as individual's engagement in both in role and extra role behaviours as team members experience more motivation through social exchange relationships with other team members and with leader. In a similar vein, Feng et al. (2016) revealed that transformational leadership helps to build teams as motivating them to learn through experimentation, exploration, and communication. Klaic et al. (2020) reckoned that transformational leadership fosters teamwork quality and better team performance in innovative tasks. Feng et al. (2016) found the association of transformational leadership with team innovative behaviours. In addition, several studies confirmed the positive linkage 
of transformational leadership with team's performance for innovative tasks (Dong et al., 2017; Lee et al., 2019; Lorinkova \& Perry, 2019). Therefore, the study proposes:

H1: Transformational leadership positively affects team effectiveness [(a) team performance, (b) quality of team experience, (c) team viability].

\section{Shared Leadership and Team Effectiveness}

Shared leadership promotes teamwork and collaboration among team members (Erkutlu, 2012). Shared leadership also improves team effectiveness by making good decisions, thanks to contributions of team members (Choi et al., 2017). Shared leadership facilitates relationship development between leaders and team members, therefore creating more comfortable working environment. In addition, the leaders with shared leadership style share their visions with team members and encourage them to engage in establishment and implementation of plans. Leader's sharing instills followers' motivation to achieve better work quality and team effectiveness (Erkutlu, 2012; Hoch, 2013). According to Pearce and Conger (2003), shared leadership is an effective leadership style in that it gives followers more authority or freedom to complete their assigned tasks and encourages them to make efforts in achieving the company's goals. Akbari et al. (2016) supported that shared leadership in teams allows for more commitment and productivity from team members. Mathieu et al. (2015) also provided empirical evidence that shared leadership is conducive to team performance. Additionally, shared leadership has been found to be conducive to objective team performance (Mehra et al., 2006), problem solving quality (Pearce et al., 2009), and satisfaction for team (Avolio et al., 1996). Therefore, the study proposes:

H2: Shared leadership positively affects team effectiveness [(a) team performance, (b) quality of team experience, (c) team viability].

\section{Teamwork Orientation as a Mediator}

Research has shown that leadership approaches executed by leader are relevant to the mentality and appreciated values of team members as followers generally strive for meeting desires by their leaders (Van Vianen, 2000) while such triggered mentality or values are conducive to performances of the team $(\mathrm{Wu}$ et al., 2010). With an emphasis on shared organisational goals, transformational leaders may arouse team members to be oriented to teamwork so as to achieve shared goals (Podsakoff et al., 1990). In addition, according to Cai et al. 
(2017), transformational leadership with a focus on group (i.e., group-based transformational leadership) likely fosters more attention of the whole team to teamwork. With an orientation to teamwork, team members are more likely to achieve higher team performance as all team members are dedicated to complete tasks of the whole team. Costa et al. (2014) indicated that with teamwork orientation, members invest more efforts in team-related tasks, and this may lead to higher team performance. Furthermore, teamwork orientation of team members also enables a shared feeling among members which helps to improve the quality of team experience. According to Driskell and Salas (1992), teamwork-oriented members likely seek inputs from other members while becoming more receptive to feedback and assistance from other team members. This helps to facilitate work process in teams (Mustafa et al., 2017) which allows for more quality of experience in teams. Additionally, when team members are oriented to teamwork, the contributions to team are larger since team members work more actively with other teammates (Mustafa et al., 2017), which allows team to have more capability to respond to changes. Therefore, we propose:

H3: Teamwork orientation mediates the relationship between transformational leadership and team effectiveness [(a) team performance, (b) quality of team experience, (c) team viability].

Fransen et al. (2018) posits that shared leadership with social-related function develops positive climate with shared values among team members while commonly-shared values attained in teams direct the whole team to achieve shared goals or forms of performances. These connections lend support for the mediating role of teamwork orientation as possessed by team members for team performance as resulted from execution of shared leadership in teams. Shared leadership facilitates teamwork and sharing among team members (Wang et al., 2017), so enabling team members to be more oriented to teamwork. Members with teamwork orientation make more contributions to team performance, team capability to respond to changes, and well-being of team like the working environment of team. According to Yukl (2002), practice of shared leadership creates favourable conditions for team members to together make efforts for achieving team's goals. This means that team members are more oriented to teamwork. When team members are all oriented to teamwork, teams likely perform well since team members act in ways that contribute to group functioning and show commitment to group goals (Bell, 2007; Mohammed \& Angell, 2004; Mustafa et al., 2017). Team members' orientation to teamwork also allows the team to adapt to changes better as every member is dedicated to maximise team's capability (Costa et al., 2014). In a team with member's high teamwork orientation, team members are likely to perceive shared goals and experience 
a sense of cohesion and social support from other team members (Mustafa et al., 2017), therefore, the quality of team experience can be improved. Hence, we propose:

H4: Teamwork orientation mediates the relationship between shared leadership and team effectiveness [(a) team performance, (b) quality of team experience, $(\mathrm{c})$ team viability].

Based on the hypotheses, the following research model is proposed:

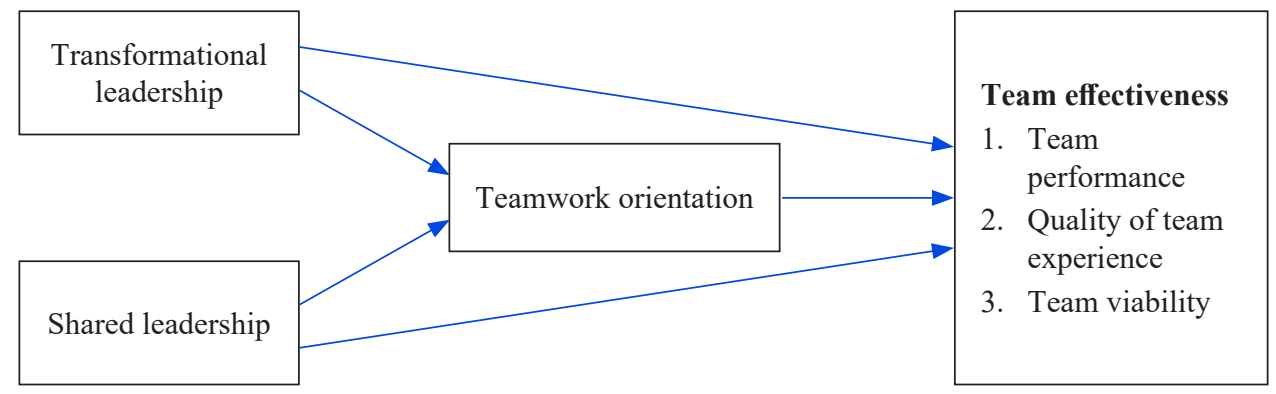

Figure 1. The research model

\section{METHODOLOGY}

\section{Sample}

Initially, the study targeted 32 companies in Hanoi, Vietnam, but only 12 companies agreed to join the research. They include two real estate companies, three educational product companies, three information technology companies, and four financial companies. These companies were targeted since the uses of working teams in these fields are viable. Teams were selected with two criteria. First, they were official working teams in companies. By the time the data were collected from the teams, they still had task interdependence. As such, teams targeted for data collection were actual or real working teams in companies. This criterion was set to guarantee that team effectiveness is crucial to these teams. Second, they had been operating for at least two months by the time they reached for data collection. This is because short working period might not allow team members to have accurate evaluation of team effectiveness.

The demographics breakdown were as follows: $57 \%$ of the respondents are female; $62 \%$ are in the age group of $25-39$ years while $23 \%$ are less than 25 years 
of age; $74 \%$ have a bachelor's degree as the highest level of education; the majority of the respondents (71\%) have the working tenure of less than two years in the present organisation. As for the teams that they were joining: $42 \%$ were in the teams of less than 5 members while $48 \%$ joined teams of 5-10 members; $63 \%$ of members worked in teams that operated less than one year; $41 \%$ of which were in the teams that operated from two to six months; $38 \%$ belonged to teams of product/service research and development; while $46 \%$ joined teams of other activities like marketing.

\section{Data Collection Procedure}

English-language questionnaires for followers was translated into Vietnamese using the back translation process, and then piloted on $18 \mathrm{MBA}$ students. The MBA students are deemed suitable for providing answers to the pilot questionnaires for two reasons. First, they are also employees working in companies in Vietnam, so they have an understanding about work configuration, including teams and situation in companies. They may have experiences in engaging teamwork in their workplaces. Second, as the students of MBA program, they become more familiar with the format and the Likert scales in the questionnaires. Obviously, with the experience in doing research and understanding about work situation, the MBA students are more likely to provide constructive comments for revising and polishing the questionnaire. The answers from these participants suggest that the respondents understood all of the questions in the questionnaires. Some minor revisions for wording of some measuring items were carried out. Specifically, wording of one item of about individualised consideration of transformational leadership, two items of shared leadership (one item about contribution to leading the team and one item about utilising team member's leadership capabilities to the fullest), and one item of quality of team experience (i.e., social climate) were slightly revised to clarify the meanings. Then, the revised questionnaires were distributed to 300 employees working in official teams of 12 companies in Vietnam. Two assistants involved in contacting respondents for data collection. These research assistants were presented about research's purposes and the measuring items. They were also guided on the way to contact companies and to approach as well as interact with respondents. These companies were contacted via phones or emails in advance to inquire about the willingness to involve in the research and the viability of working teams in companies. Of 32 companies contacted, 12 companies agreed to join the research. When arriving in companies, the research assistants asked the contact people or representatives of the companies on the information of the working teams, particularly the number of formal working teams and the members working in those teams. Later, the research assistants met the team members in 
person to ask for questionnaire completion. It took about five minutes for each respondent to answer a questionnaire. The completed questionnaires were then generated by the research assistants. For most of the teams targeted, the responses are generated from all of the team members. In some cases, when some team members were absent during data collection visits, the questionnaires were left to the contact person or representative of the company for sending to the absent member, and later collected via mail or in person by the research assistants. The answers collected from team members were later coded as a data set. Of 300 questionnaires distributed, 279 responses from 43 teams were collected, giving the response rate of $93 \%$. Twenty-six teams have the number of team members of three to five persons, of which the teams of five members account for the most with 15 teams, followed by nine teams of four members and two teams of three members. The remaining 17 teams have the team members ranging from 6 to 10 . Of these 17 teams, 5 teams have 10 members while the number of teams with 6,7 , and 8 members is rather similar with the values of 5,4 , and 3, respectively. Six questionnaires were excluded because they contained missing answers or wrong answers. Subsequently, 273 valid responses were kept for data analyses.

\section{Measure}

Transformational leadership was measured with 12 items adapted from Bass and Avolio (1990); a sample item is "My leader suggests new ways of looking at how to complete assignments." Shared leadership was measured with 13 items adapted from Small (2007); a sample item is "To ensure that a team will be effective, the leadership role should rotate among team members." Eight items were reversely coded due to their negative wording. Six items adapted from Mustafa et al. (2017) were used to measure teamwork orientation; a sample item is "I feel positive about working in a team." Team effectiveness was measured with 10 items indicating team performance ( 3 items), quality of team experience ( 3 items), and team viability ( 4 items). These items were adapted from Aubé and Rousseau (2005). A sample item of team performance is "The members of this team produce quality work." A sample measuring item of quality of team experience is "The social climate in our work team is good." A sample item of team viability is "Team members adjust to the changes that happen in their work environment." All items were measured on a 5-point Likert scale with 1 = strongly disagree; 2 = disagree; 3 = undecided; 4 = agree; $5=$ strongly agree. 


\section{Assessment of Common Method Variance}

The study assessed common method variance using Harman's single factor test for all of the measuring items. The results indicate that no factor accounted for the majority of the variance. An un-rotated factor analysis showed seven factors accounting for $58 \%$ of the total variance (higher than the criterion of $50 \%$ ). The largest factor explained $29 \%$ of the variance which is lower than the cut-off of $50 \%$. These suggest that common method variance did not affect this analysis. Variance inflation factors (VIF) were also calculated to check for multicollinearity, and the obtained results reveal that VIF values ranged from 1.288 to 1.883 which are much lower than the cut-off of 10 . These values contributively explained that multicollinearity did not affect this analysis.

\section{RESULTS}

The Cronbach's alpha values of the constructs are all higher than .70, suggesting reliability of the study's variables. Exploratory factor analysis (EFA) was carried out. The results indicated that six variables emerged with the variance percentage of $58 \%$. The largest factor explains $29 \%$ of variance. One item of shared leadership was deleted due to its low loading. In terms of contents, the deleted item entails two levels of negation for accentuating the advantage of shared leadership which might raise some difficulty for employees to respond. The results of EFA show convergent validity of the measuring items for all of the constructs. The correlational matrix also shows significant correlations among all of the constructs.

Table 1

Correlational matrix of the study constructs

\begin{tabular}{lcccccccc}
\hline Constructs & Mean & SD & 1 & 2 & 3 & 4 & 5 & 6 \\
\hline 1. Transformational & 3.873 & .569 & .889 & & & & & \\
$\quad$ leadership & & & & & & & & \\
2. Shared leadership & 3.101 & .669 & $.310^{* *}$ & .892 & & & & \\
3. Teamwork orientation & 3.974 & .537 & $.335^{* *}$ & $.466^{* *}$ & .914 & & & \\
4. Team performance & 3.728 & .643 & $.335^{* *}$ & $.319^{* *}$ & $.375^{* *}$ & .875 & & \\
5. Quality of team & 3.541 & .713 & $.380^{* *}$ & $.338^{* *}$ & $.380^{* *}$ & $.360^{* *}$ & .826 & \\
$\quad$ experience & & & & & & & & \\
6. Team viability & 3.716 & .876 & $.473^{* *}$ & $.496^{* *}$ & $.429^{* *}$ & $.497^{* *}$ & $.478^{* *}$ & .894 \\
\hline
\end{tabular}

Note: $N=273$; the values in diagonal lines are Cronbach's alpha values; ${ }^{* *} p<.01$ 
Confirmatory factor analysis (CFA) was carried out, and the obtained results showed that measuring items loaded in their proper factors with acceptable loading coefficients (above .50). Fit indices of the model with six factors consist of $\chi^{2}=1070.760 ; d f=725 ; \chi^{2} / d f=1.477$; GFI $=.842$; IFI $=.938$; TLI $=.932$; and CFI $=.937$. For a comparative view, a model of five factors (merging transformational leadership and shared leadership into one factor) was tested, and the fit indices is much lower than the model with six factors $\left(\chi^{2}=1941.598\right.$; $d f=730 ; \chi^{2} / d f=2.660 ; \mathrm{GFI}=.598 ; \mathrm{IFI}=.781 ; \mathrm{TLI}=.764$; CFI $\left.=.779\right)$. The fit indices suggest that the six factor model is a better fit with the data. To test the hypotheses initially proposed, the study used structural equation modelling (SEM) in AMOS. The results suggested an acceptable model with $\chi^{2}=1117.067$; $d f=728 ; \chi^{2} / d f=1.534 ; \mathrm{GFI}=.833 ;$ AGFI $=.812 ;$ IFI $=.930 ;$ TLI $=.924 ;$ CFI $=.929$; and RMSEA $=.044$. Two alternative models were tested for a comparison with the proposed model. In the first model, teamwork orientation was treated as an ultimate outcome like outcomes of team effectiveness rather than as a mediating variable, and the fit indices of GFI $=.829$; IFI $=.927$; TLI $=.921$; and CFI $=.926$ are not as high as those of the proposed model. Similarly, the second alternative model with teamwork orientation as a mediator but no direct linkages between transformational leadership, shared leadership and team effectiveness also shows lower fit indices with GFI $=.830$; IFI $=.924$; TLI $=.918$; and CFI $=.924$. So, the proposed model has the highest fitness with the data generated. The results indicate that transformational leadership and shared leadership are significantly relevant to all the three dimensions of team effectiveness including team performance, quality of team experience, and team viability. Remarkably, the effects of transformational leadership are all higher than those of shared leadership for all the three dimensions of team performance, quality of team experience, and team viability. Furthermore, among the three dimensions of team effectiveness, team viability is the most associated to transformational leadership and shared leadership with the coefficients of .618 and .412 , respectively. Meanwhile, for quality of team experience, transformational leadership is dramatically relevant with the coefficient of .432 while the effect of shared leadership is rather modest with the coefficient of .197. These empirical results confirm H1 and H2. 
Thi Bich Hanh Tran and Anh Dung Vu

Table 2

Summary of hypothesis testing

\begin{tabular}{llccc}
\hline Relationships & & Coefficients & t-values & Outcomes \\
\hline $\begin{array}{l}\text { Transformational } \\
\text { leadership }\end{array}$ & $\rightarrow$ Team performance (H1a) & $.293^{* * *}$ & 3.445 & Supported \\
$\begin{array}{l}\text { Transformational } \\
\text { leadership }\end{array}$ & $\rightarrow \begin{array}{l}\text { Quality of team experience } \\
\text { (H1b) }\end{array}$ & $.432^{* * *}$ & 4.324 & Supported \\
$\begin{array}{l}\text { Transformational } \\
\text { leadership }\end{array}$ & $\rightarrow$ Team viability (H1c) & $.618^{* * *}$ & 5.618 & Supported \\
Shared leadership & $\rightarrow$ Team performance (H2a) & $.151^{*}$ & 2.235 & Supported \\
Shared leadership & $\rightarrow \begin{array}{l}\text { Quality of team experience } \\
\text { (H2b) }\end{array}$ & $.197^{*}$ & 2.536 & Supported \\
Shared leadership & $\rightarrow$ Team viability (H2c) & $.412^{* * *}$ & 4.835 & Supported \\
\hline
\end{tabular}

Note: ${ }^{*} p<.05 ;{ }^{* *} p<.01 ;{ }^{* * *} p<.001$

To test the mediating role of teamwork orientation, the study employed bootstrapping tests with the boostrap sample of 5,000 in AMOS. Six mediation analyses were conducted between the two specific leadership styles and three components of team effectiveness. In each analysis, two steps were carried out. In the first step, only the direct effect was tested with the empirical data. In the second step, the mediating variable of teamwork orientation was added into the initial model with the direct effect. Results in Table 3 show that effects of leadership styles on dimensions of team effectiveness have been dramatically reduced when teamwork orientation is inserted. As all of the indirect effects are significant, the study concludes that teamwork orientation is a significant mediator between transformational leadership, shared leadership, and team effectiveness. As both the direct effect and indirect effect are positive (in the same direction) and are significant, the study concludes that teamwork orientation is a partial mediator between transformational leadership, shared leadership, and dimensions of team effectiveness, including team performance, quality of team experience, and team viability (Zhao et al., 2010). 
Table 3

Mediating role of teamwork orientation

\begin{tabular}{|c|c|c|c|c|c|c|c|}
\hline \multirow{2}{*}{\multicolumn{5}{|c|}{ Mediating effects }} & \multicolumn{2}{|c|}{ Coefficients } & \multirow{2}{*}{$\begin{array}{l}\text { Types of } \\
\text { mediation }\end{array}$} \\
\hline & & & & & Indirect & Direct & \\
\hline $\begin{array}{l}\text { Transformational } \\
\text { leadership }\end{array}$ & $\rightarrow$ & $\begin{array}{l}\text { Teamwork } \\
\text { orientation }\end{array}$ & $\rightarrow$ & $\begin{array}{l}\text { Team performance } \\
(\mathrm{H} 3 \mathrm{a})\end{array}$ & $.092^{* * *}$ & $.309^{* * *}$ & Partial \\
\hline $\begin{array}{l}\text { Transformational } \\
\text { leadership }\end{array}$ & $\rightarrow$ & $\begin{array}{l}\text { Teamwork } \\
\text { orientation }\end{array}$ & $\rightarrow$ & $\begin{array}{l}\text { Quality of team } \\
\text { experience (H3b) }\end{array}$ & $.152^{* * *}$ & $.495^{* * *}$ & Partial \\
\hline $\begin{array}{l}\text { Transformational } \\
\text { leadership }\end{array}$ & $\rightarrow$ & $\begin{array}{l}\text { Teamwork } \\
\text { orientation }\end{array}$ & $\rightarrow$ & Team viability $(\mathrm{H} 3 \mathrm{c})$ & $.184^{* * *}$ & $.858^{* * *}$ & Partial \\
\hline Shared leadership & $\rightarrow$ & $\begin{array}{l}\text { Teamwork } \\
\text { orientation }\end{array}$ & $\rightarrow$ & $\begin{array}{l}\text { Team performance } \\
(\mathrm{H} 4 \mathrm{a})\end{array}$ & $.076^{* * *}$ & $.182^{* * *}$ & Partial \\
\hline Shared leadership & $\rightarrow$ & $\begin{array}{l}\text { Teamwork } \\
\text { orientation }\end{array}$ & $\rightarrow$ & $\begin{array}{l}\text { Quality of team } \\
\text { experience }(\mathrm{H} 4 \mathrm{~b})\end{array}$ & $.135^{* * *}$ & $.330^{* * *}$ & Partial \\
\hline Shared leadership & $\rightarrow$ & $\begin{array}{l}\text { Teamwork } \\
\text { orientation }\end{array}$ & $\rightarrow$ & Team viability $(\mathrm{H} 4 \mathrm{c})$ & $.139^{* *}$ & $.553^{* * *}$ & Partial \\
\hline
\end{tabular}

Note: ${ }^{*} p<.05 ;{ }^{* *} p<.01 ;{ }^{* * *} p<.001$

\section{DISCUSSION}

According to Choi et al. (2017), transformational leadership is a vertical leadership stemming from the leader of teams; whereas, shared leadership is a horizontal leadership approach that originates from team members. Though the two leadership styles create tremendous motivations for followers in work, each style catalyses different consequences. Even in the case the two styles affect a common outcome, the magnitudes of the effects are not equal. This research showed that both transformational leadership and shared leadership are positively linked to team effectiveness, but effect of each style varies. Specifically, transformational leadership creates more positive effects on all the three dimensions of team effectiveness, specifically team performance, quality of team experience, and team viability compared to shared leadership. This study's finding of the positive relationship between transformational leadership and team performance is concurrent with Choi et al.'s (2017) finding on the transformational leadership - team output performance linkage. However, the present study's finding is valuable such that the relationship is validated in an emerging Asian economy with inadequate attention of leadership researchers. Recently, Wang and Howell (2010) proposed a new conceptualisation of dual level transformational leadership comprising group-focused transformational 
leadership and individual-focused transformational leadership. A substantial number of studies have been recently added to explore and validate the differential effects of these two sub-elements on organisational outcomes as well as team performances (Cai et al., 2017; Jiang et al., 2015; Klaic et al., 2018). Though the measure of transformational leadership with four components of idealised influence, inspirational motivation, intellectual stimulation, and individual consideration that the present study employed is still more popularly used, and its four components seem more specific for applications in practice, to gain another insight into the phenomenon, future research may evaluate the differential effects of group-focused versus individual-focused transformational leadership on team performances.

In contrast, while Choi et al. (2017) reckoned that shared leadership did not have a significant effect on output performance but was significantly associated to process performance, the present study's findings varied to which shared leadership is significantly related to team performance. The finding of significant effect of shared leadership on quality of team experience and team viability is in line with Choi et al.'s (2017) finding that shared leadership is conducive to process performance of team. Nevertheless, the current study's findings offer an insight into the effect with the specific outcomes, namely quality of team experience and team viability. Also, compared to the results from Choi et al.'s (2017) study, the present study's finding that transformational leadership is significantly related to quality of team experience and team viability somewhat varies as Choi et al. (2017) found the non-significant influence of transformational leadership on organising and planning effectiveness of teams.

However, the study's results show that to enhance team effectiveness including team performance, quality of team experience, and team viability, execution of transformational leadership will create more effectiveness compared to application of shared leadership. These results are partly concurrent with Choi et al.'s (2017) finding that transformational leadership catalyses more overall team performance in comparison with shared leadership. The difference in the findings of the present study can be resorted to the different samples. In Vietnam, the concept of sharing leading position, taking turns in leading teams, or rotating leader role in teamwork is still new, so shared leadership is not highly evaluated or expected to bring about positive outcomes. In fact, up to the present, there has been no specific study about shared leadership in Vietnamese context or empirical evidence of application of this leadership style in enterprises in Vietnam. Besides, interesting discussions by Morgeson et al. (2009) in an integrative review of research of leadership offer more supporting evidence that compared to shared leadership with a more informal nature, 
transformational leadership as a formal vertical leadership approach can be more effective for meeting the team's needs or function of developing teams (i.e., for team viability), defining missions for teams, and providing feedbacks which are crucial elements for team performances. As such, the empirical results of the present study validate the observation by Morgeson et al. (2009) for the source of leadership to be best positioned to perform a particular leadership function. Nevertheless, according to Morgeson et al. (2009), for other team leadership functions like encouraging team self-management and performing team tasks, a more informal leadership approach like shared leadership can be more effective. This suggests that future research should consider specific team functions or needs, for example the 15 team functions identified by Morgeson et al. (2009) when comparing effectiveness of differential leadership approaches like transformational leadership and shared leadership.

The study's results also reveal that teamwork orientation is a significant mechanism for all three facets of team effectiveness. Nevertheless, the magnitudes of the effects are not large. This means that though teamwork orientation is a mechanism for explicating effects of transformational leadership and shared leadership on dimensions of team effectiveness, teamwork orientation is not the key mechanism that can explain dramatic effect for team effectiveness. There can be another mechanism that can explicate the major influences of these two leadership styles on dimensions of team effectiveness. Future research should investigate other mechanisms such as trust in leaders, organisational commitment, and etc.

Research on leadership has been well-developed with ample empirical studies on specific leadership styles/approaches and conceptual papers. Nonetheless, by dedicating to transformational leadership and shared leadership, this study positively contributes to literature of leadership. The comparative research on these two leadership approaches is suitable in teamwork because transformational leadership has been well-known to be effective for achieving organisational goals, including team's goals (Aryee et al., 2012). Meanwhile, shared leadership is considered to create the most effects for teamwork environment because team's duties often require team members to closely cooperate (Houghton et al., 2003). By evaluating both leadership approaches on a certain category of outcomes, the present study offers a comparative view for the effects, and so providing an insight into the phenomenon of application of leadership approaches in Vietnam. This is particularly valuable because there exists little evidence of application and effectiveness of leadership in Vietnam. For example, while GLOBE study evaluated relevance of leadership approaches in 66 countries in the world, Vietnam was not included, and so little information was detected about effectiveness of leadership approaches in Vietnam. 
Similar to other Asian countries inclusive of China, South Korea, Taiwan, Singapore, and Japan with a culture characterised by Confucian influence, collectivism, and high power distance (Choi et al., 2017; Gupta et al., 2002; Park et al., 2018), vertical and supportive leadership approach like transformational leadership is more favoured compared to horizontal approach (i.e., shared leadership) in Vietnam. For instance, while Japanese employees prefer equality, mutual responsibility, and shared leadership (Carson et al., 2007), supportive leadership still exerts a substantially higher effect on satisfaction level of work performance of Japanese followers in teams compared to a non-significant effect for other countries like Taiwan, South Korea, and United States (Dorfman et al., 1997). Besides, Ishikawa (2012) and Wendt et al. (2009) also added the supporting evidence that supportive leadership positively affects quality of communication processes in teams in Japan. The results of the present study for the significant effect of transformational leadership are also similar to observations by Euwema et al. (2007), Hwang et al. (2015), and Joo (2010). Lee et al. (2014) found that such supportive leadership positively leads to team performances in Korean context, performance of extra-role duties as well as quality relationships amongst team members in Singapore context (Euwema et al., 2007), and performances of members in China context (Hwang et al., 2015). However, the results of the present study featuring effectiveness of transformational leadership versus shared leadership are somewhat varied from other Asian contexts with different national characteristics including social and historical background. Specifically, as one of the oldest civilisations in Asia with a heritage spanning several centuries, Vietnam has deeply ingrained values and beliefs in its typical culture including respect for authority, hierarchical order, collectiveness consensus, cooperation, long-term commitment while the degrees of these values are not identical to other Asian countries. Nevertheless, with economic reform implemented from 1986 for transitioning the economy from centrally planned to market-based economy, the entrance of multinational companies with Westernised human resource management practices, and the development of generational values (generations $\mathrm{Y}$ and $\mathrm{Z}$ dominating labour market for service enterprises) (Cox et al., 2014; Vo, 2009), emergent values like empowerment and individual consideration by supervisors can be gradually recognised and emphasised. In this way, the relevance of transformational leadership and shared leadership for Vietnamese context will become more pronounced, and the present study's findings partially prove this characteristic. 


\section{CONCLUSION}

\section{Theoretical Implications}

This study has three theoretical contributions. First, this is the first study to assess the impact of transformational leadership and shared leadership on quality of team experience and team viability. This attempt is valuable in two ways. It prompts future research to delve into other categories of team effectiveness, akin to output performance and process performance like prior research (Choi et al., 2016). Moreover, by offering a comparative evaluation of transformational leadership and shared leadership, the study might inspire future studies to consider examining these two leadership styles in other contexts. Second, this is the first research to evaluate the mediating role of teamwork orientation in the effect of transformational leadership and shared leadership. It adds to the extant literature a possible mechanism for team effectiveness, and therefore attract future research's attention on this mechanism when examining other team-related outcomes. Third, the study provides interesting empirical evidence of Vietnamese context which has different economic and cultural characteristics from Western and developed economies (Choi et al., 2016). As such, the study enriched the empirical data base of leadership. Following the study's attempt, future research may conduct an investigation of the similar model with sample of different under-explored contexts or compare the robustness of the effects of the models with cross-cultural samples.

\section{Managerial Implications}

Based on the findings, the study suggests the following implications for team leaders, managers in enterprises in Vietnam and in other economies with somewhat similar economic and cultural characteristics. First, team leaders need to be aware that their leadership styles are influential to team effectiveness, and execution of different leadership styles may yield different results with dimensions of team effectiveness including team performance, quality of team experience, and team viability. Therefore, team leaders need to be flexible in performing their leadership styles. While execution of leadership styles also depends on characteristics of followers, as the study shows that transformational leadership is more effective than shared leadership in with the selected Vietnamese sample, leaders should be aware of superior effectiveness of transformational leadership and consider to apply this leadership style in specific situations of workplaces. Second, when applying a specific leadership style like transformational leadership or shared leadership, team leaders should stress the significance of teamwork orientation among team members so that every team 
member can channel their efforts and orientation towards teamwork. This is because followers tend to make efforts to fulfill leader's needs and attend to what leaders emphasise (Van Vianen, 2000). Third, leaders and human resource managers can organise seminars and short training courses on leadership for team leaders and potential employees to attain knowledge and develop skills of leadership.

\section{Study Limitations and Recommendations for Future Research}

The present study has three main limitations. First, the data were merely collected from a source of team members of formal teams in companies. To enhance objectivity, future research may collect data from both team leaders and team members. For example, leadership approaches can be evaluated from team members while team performance may be assessed by leaders. Second, as a cross-sectional study with the data collected from one time, the results of this research is limited from interpretation of causality. As prior studies indicated, leadership within a team can shift over time (Aime et al., 2014; DeRue et al., 2015), and longitudinal research design may help to understand how leadership approaches emerge and develop overtime (Carson et al., 2007; Mehra et al., 2006). Future research may have a design with longitudinal research to observe whether over time the two leadership approaches will enhance dimensions of team effectiveness or not. Third, the sample of the study is quite modest though it met criteria for data analyses. Due to the modest sample, the findings of the study cannot be generalised to the whole Vietnamese context with various industries and different areas. Ideally, future studies should examine the phenomenon with a larger, more diverse sample.

\section{REFERENCES}

Aime, F., Humphrey, S., DeRue, D. S., \& Paul, J. B. (2014). The riddle of heterarchy: Power transitions in cross-functional teams. Academy of Management Journal, 57, 327-352. https://doi.org/10.5465/amj.2011.0756

Akbari, M., Kashani, S. H., \& Chaijani, M. H. (2016). Sharing, caring, and responsibility in higher education teams. Small Group Research, 47, 542-568. https://doi.org/ $10.1177 / 1046496416667609$

Aubé, C., \& Rousseau, V. (2005). Team goal commitment and team effectiveness: The role of task interdependence and supportive behaviors. Group Dynamics: Theory, Research, and Practice, 9(3), 189-204. https://doi.org/10.1037/1089 $-2699.9 .3 .189$ 
Aryee, S., Walumbwa, F. O., Zhou, Q., \& Hartnell, C. A. (2012). Transformational leadership, innovative behavior, and task performance: Test of mediation and moderation processes. Human Performance, 25, 1-25. https://doi.org/10.1080/ 08959285.2011 .631648

Avolio, B. J., Jung, D. I., Murry, W., \& Sivasubramaniam, N. (1996). Building highly developed teams: Focusing on shared leadership processes, efficacy, trust, and performance. Advances in Interdisciplinary Studies of Work Teams, 3, 173-209.

Bain, P. G., Mann, L., Atkins, L., \& Dunning, J. (2005). R\&D project leaders: Roles and responsibilities. In L. Mann (Ed.), Leadership, management, and innovation in $R \& D$ project teams (pp. 49-70). Westport, CT: Praeger.

Bass, B. M., \& Avolio, B. J. (1990). Developing transformational leadership: 1992 and Beyond. Journal of European Industrial Training, 14(5), 21-27. https://doi.org/10.1108/03090599010135122

Bell, S. T. (2007). Deep-level composition variables as predictors of team performance: A meta-analysis. Journal of Applied Psychology, 92(3), 595-615. https://doi .org/10.1037/0021-9010.92.3.595

Bergman, J. Z., Rentsch, J. R., Small, E. E., Davenport, S. W., \& Bergman, S. M. (2012). The shared leadership process in decision-making teams. The Journal of Social Psychology, 152, 17-42. https://doi.org/10.1080/00224545.2010.538763

Bligh, M. C., Pearce, C. L., \& Kohles, J. C. (2006). The importance of self-and-shared leadership in team-based knowledge work: A meso-level model of leadership dynamics. Journal of Managerial Psychology, 21, 296-318. https://doi.org/ 10.1108/02683940610663105

Braun, S., Peus, C., Weisweiler, S., \& Frey, D. (2013). Transformational leadership, job satisfaction, and team performance: A multilevel mediation model of trust. The Leadership Quarterly, 24(1), 270-283. https://doi.org/10.1016/ j.leaqua.2012.11.006

Burke, C. S., Stagl, K. C., Klein, C., Goodwin, G. F., Salas, E., \& Halpin, S. M. (2006). What type of leadership behaviors are functional in teams? A meta-analysis. The Leadership Quarterly, 17, 288-307. https://doi.org/10.1016/j.leaqua.2006 .02 .007

Cai, Y., Jia, L., \& Li, J. (2017). Dual-level transformational leadership and team information elaboration: The mediating role of relationship conflict and moderating role of middle way thinking. Asia Pacific Journal of Management, 34, 399-421. https://doi.org/10.1007/s10490-016-9492-X

Campion, M. A., Medsker, G. J., \& Higgs, A. C. (1993). Relations between work group characteristics and effectiveness: Implications for designing effective work groups. Personnel Psychology, 46(4), 823-850. https://doi .org/10.1111/j.1744-6570.1993.tb01571.x

Carson, J. B., Tesluk, P. E., \& Marrone, J. A. (2007). Shared leadership in teams: An investigation of antecedent conditions and performance. Academy of Management Journal, 50, 1217-1234. 
Choi, S. B., Kim, K. H., \& Kang, S. W. (2017). Effects of transformational and shared leadership styles on employees' perception of team effectiveness. Social Behavior \& Personality: An International Journal, 45(3), 377-386. https://doi .org/10.2224/sbp.5805

Choi, S. B., Tran, T. B. H., \& Kang, S. W. (2016). Inclusive leadership and employee well-being: The mediating role of person-job fit. Journal of Happiness Studies, 17(6), 1877-1901. https://doi.org/10.1007/s10902-016-9801-6

Chun, J. U., Cho, K., \& Sosik, J. J. (2016). A multilevel study of group-focused and individual-focused transformational leadership, social exchange relationships, and performance in teams. Journal of Organizational Behavior, 37, 374-396. https://doi.org/10.1002/job.2048

Costa, P. L., Passos, A. M., \& Bakker, A. B. (2014). Teamwork engagement: A model of emergence. Journal of Occupational and Organizational Psychology, 87(2), 414-436. https://doi.org/10.1111/joop.12057

Contractor, N. S., DeChurch, L. A., Carson, J., Carter, D. R., \& Keegan, B. (2012). The topology of collective leadership. The Leadership Quarterly, 23(6), 994-1011. https://doi.org/10.1016/j.leaqua.2012.10.010

Cox, A., Hannif, Z., \& Rowley, C. (2014). Leadership styles and generational effects: Examples of US companies in Vietnam. The International Journal of Human Resource Management, 25(1), 1-22. https://doi.org/10.1080/09585192.2013 .778311

Day, D. V. (2012). Leadership. In S. W. J. Kozlowski (Ed.), The Oxford handbook of organizational psychology (vol. 1, pp. 696-729). New York: Oxford University. https://doi.org/10.1093/oxfordhb/9780199928309.013.0022

DeRue, D. S., Nahrgang, J. D., \& Ashford, S. J. (2015). Interpersonal perceptions and the emergence of leadership structures in groups: A network perspective. Organization Science, 26(4), 1192-1209. https://doi.org/10.1287/orsc.2014 .0963

Dong, Y., Bartol, K. M., Zhang, Z.-X., \& Li, C. (2017). Enhancing employee creativity via individual skill development and team knowledge sharing: Influences of dualfocused transformational leadership. Journal of Organizational Behavior, 38, 439-358. https://doi.org/10.1002/job.2134

Dorfman, P. W., Howell, J. P., Hibino, H., Lee, J. K., Tate, U., \& Bautista, A. (1997). Leadership in Western and Asian countries: Commonalities and differences in effective leadership processes across cultures. The Leadership Quarterly, 8(3), 233-274. https://doi.org/10.1016/S1048-9843(97)90003-5

Driskell, J. E., \& Salas, E. (1992). Collective behavior and team performance. Human Factors, 34(3), 277-288. https://doi.org/10.1177/001872089203400303

Earley, P. C., \& Gibson, C. B. (1998). Taking stock in our progress on individualismcollectivism: 100 years of solidarity and community. Journal of Management, 24(3), 265-304. https://doi.org/10.1016/S0149-2063(99)80063-4

Eby, L. T., \& Dobbins, G. H. (1997). Collectivistic orientation in teams: An individual and group-level analysis. Journal of Organizational Behavior, 18(3), 275-295. https://doi.org/10.1002/(SICI)1099-1379(199705)18:3\%3C275::AID-JOB796 \%3E3.0.CO;2-C 
Erkutlu, H. (2012). The impact of organizational culture on the relationship between shared leadership and team proactivity. Team Performance Management: An International Journal, 18, 102-119. https://doi.org/10.1108/13527591211207734

Euwema, M. C., Wendt, H., \& Van Emmerik, H. (2007). Leadership styles and group organizational citizenship behavior across cultures. Journal of Organizational Behavior, 28(8), 1035-1057.

Faraj, S., \& Sproull, L. (2000). Coordinating expertise in software development teams. Management Science, 46(12), 1554-1568. https://doi.org/10.1287/mnsc.46.12 .1554 .12072

Feng, C., Huang, X., \& Zhang, L. (2016). A multilevel study of transformational leadership, dual organizational change and innovative behavior in groups. Journal of Organizational Change Management, 29, 855-877. https://doi.org/ 10.1108/JOCM-01-2016-0005

Fransen, J., Kirschner, P. A., \& Erkens, G. (2011). Mediating team effectiveness in the context of collaborative learning: The importance of team and task awareness. Computers in Human Behavior, 27(3), 1103-1113. https://doi.org/10.1016/ j.chb.2010.05.017

Fransen, K., Delvaux, E., Mesquita, B., \& Van Puyenbroeck, S. (2018). The emergence of shared leadership in newly formed teams with an initial structure of vertical leadership: A longitudinal analysis. Journal of Applied Behavioral Science, 54, 140-170. https://doi.org/10.1177/0021886318756359

Gupta, V., Surie, G., Javidan, M. \& Chhokar, J. (2002). Southern Asia cluster: Where the old meets the new? Journal of World Business, 37(1), 16-27. https://doi.org/10.1016/S1090-9516(01)00071-2

Hackman, M. Z., \& Johnson, C. E. (2013). Leadership: A communication perspective (6th ed.). Long Grove, IL: Waveland Press.

Han, S. J., Lee, Y., \& Beyerlein, M. (2019). Developing team creativity: The influence of psychological safety and relation-oriented shared leadership. Performance Improvement Quarterly, 32, 159-182. https://doi.org/10.1002/piq.21293

Hoch, J. E. (2013). Shared leadership and innovation: The role of vertical leadership and employee integrity. Journal of Business and Psychology, 28, 159-174. https://doi.org/10.1007/s10869-012-9273-6

Houghton, J. D., Neck, C. P., \& Manz, C. C. (2003). Self-leadership and super leadership: The heart and art of creating shared leadership in teams. In C. L. Peace, \& J. A. Conger (Eds.), Shared leadership: Reframing the hows and whys of leadership (pp. 123-140). Thousand Oaks, CA: Sage. https://doi.org/ 10.4135/9781452229539.n6

Hwang, S. J., Quast, L. N., Center, B. A., Chung, C. T. N., Hahn, H. J., \& Wohkittel, J. (2015). The impact of leadership behaviours on leaders' perceived job performance across cultures: Comparing the role of charismatic, directive, participative, and supportive leadership behaviours in the US and four Confucian Asian countries. Human Resource Development International, 18(3), 259-277. https://doi.org/10.1080/13678868.2015.1036226 
Ishikawa, J. (2012). Leadership and performance in Japanese R\&D teams. Asia Pacific Business Review, 18(2), 241-258. https://doi.org/10.1080/13602381.2010 .532907

Jiang, W., Gu, Q., Wang, G. G. (2015). To guide or to divide: The dual-side effects of transformational leadership on team innovation. Journal of Business and Psychology, 30, 677-691. https://doi.org/10.1007/s10869-014-9395-0

Joo, B. K. B. (2010). Organizational commitment for knowledge workers: The roles of perceived organizational learning culture, leader-member exchange quality, and turnover intention. Human Resource Development Quarterly, 21(1), 69-85. https://doi.org/10.1002/hrdq.20031

Klaic, A., Burtscher, M. J., \& Jonas, K. (2018). Person-supervisor fit, needs-supplies fit, and team fit as mediators of the relationship between dual-focused transformational leadership and well-being in scientific teams. European Journal of Work and Organizational Psychology, 27, 669-682. https://doi.org/ 10.1080/1359432X.2018.1502174

Klaic, A., Burtscher, M. J., \& Jonas, K. (2020). Fostering team innovation and learning by means of team-centric transformational leadership: The role of teamwork quality. Journal of Occupational and Organizational Psychology. Advance online publication. https://doi.org/10.1111/joop.12316

Koch, C. L. Y., \& van Straten, E. (1997). Personeelsbeleid in enkele MKB-bedrijven' [Personnel management in several SMEs] (EIM Strategic Study 9703, Zoetermeer). The Netherlands: EIM.

Kozlowski, S. W. J., Mak, S., \& Chao, G. T. (2016). Team-centric leadership: An integrative review. Annual Review of Organizational Psychology and Organizational Behavior, 3, 21-54. https://doi.org/10.1146/annurev-orgpsych-041015-062429

Lee, E. K., Avgar, A. C., Park, W.-W., \& Choi, D. (2019). The dual effects of task conflict on team creativity. International Journal of Conflict Management, 30, 132-154. https://doi.org/10.1108/IJCMA-02-2018-0025

Lee, J., Lee, H., \& Park, J. G. (2014). Exploring the impact of empowering leadership on knowledge sharing, absorptive capacity and team performance in IT service. Information Technology \& People, 27(3), 366-386. https://doi.org/10 $.1037 / \mathrm{t} 38360-000$

Li, C., Zhao, H., \& Begley, T. M. (2015). Transformational leadership dimensions and employee creativity in China: A cross-level analysis. Journal of Business Research, 68(6), 1149-1156.

Lorinkova, N. M., \& Perry, S. J. (2019). The importance of group-focused transformational leadership and felt obligation for helping and group performance. Journal of Organizational Behavior, 40, 231-247. https://doi.org/10.1002/job.2322

Madhavan, R., \& Grover, R. (1998). From embedded knowledge to embodied knowledge: New product development as knowledge management. Journal of Marketing, 62, 1-12. https://doi.org/10.2307/1252283

Mathieu, J., Maynard, M. T., Rapp, T., \& Gilson, L. (2008). Team effectiveness 19972007: A review of recent advancements and a glimpse into the future. Journal of Management, 34(3), 410-476. https://doi.org/10.1177/0149206308316061 
Mathieu, J. E., Kukenberger, M. R., D’Innocenzo, L., \& Reilly, G. (2015). Modeling reciprocal team cohesion-performance relationships, as impacted by shared leadership and members' competence. Journal of Applied Psychology, 100, 713-734. https://doi.org/10.1037/a0038898

Mehra, A., Smith, B. R., Dixon, A. L., \& Robertson, B. (2006). Distributed leadership in teams: The network of leadership perceptions and team performance. Leadership Quarterly, 17, 232-245. https://doi.org/10.1016/j.leaqua.2006.10.011 and https://doi.org/10.1016/j.leaqua.2006.02.003

Mesu, J., Sanders, K., \& Riemsdijk, M. V. (2015). Transformational leadership and organisational commitment in manufacturing and service small to mediumsized enterprises: The moderating effects of directive and participative leadership. Personnel Review, 44(6), 970- 990. https://doi.org/10.1108/PR01-2014-0020

Mohammed, S., \& Angell, L. C. (2004). Surface-and deep-level diversity in workgroups: Examining the moderating effects of team orientation and team process on relationship conflict. Journal of Organizational Behavior, 25(8), 1015-1039. https://doi.org/10.1002/job.293

Morgeson, F. P., DeRue, D. S., \& Karam, E. P. (2009). Leadership in teams: A functional approach to understanding leadership structures and processes. Journal of Management, 36(1), 1-39. https://doi.org/10.1177/0149206309347376

Mustafa, G., Glavee-Geo, R., \& Rice, P. M. (2017). Teamwork orientation and personal learning: The role of individual cultural values and value congruence. SA Journal of Industrial Psychology, 43, 1-13. https://doi.org/10.4102/sajip .v43i0.1446

Park, S., Han, S. H., Hwang, S. J., \& Park, C. K. (2018). Comparison of leadership styles in Confucian Asian countries. Human Resource Development International, 22(1), 91-100. https://doi.org/10.1080/13678868.2018.1425587

Pearce, C. L. (2004). The future of leadership: Combining vertical and shared leadership to transform knowledge work. Academy of Management Executive, 18(1), 47-57. https://doi.org/10.5465/ame.2004.12690298

Pearce, C. L., \& Conger, J. A. (2003). All those years ago: The historical underpinnings of shared leadership. In C. L. Pearce, \& J. A. Conger (Eds.), Shared leadership: Reframing the hows and whys of leadership (pp. 1-18). Thousand Oaks, CA: Sage. https://doi.org/10.4135/9781452229539.n1

Pearce, C. L., Manz, C. C., \& Sims, H. P. (2009). Where do we go from here? Is shared leadership the key to team success. Organisational Dynamics, 38(3), 234-238. https://doi.org/10.1016/j.orgdyn.2009.04.008

Pearce, C. L., \& Sims, H. P., Jr. (2002). Vertical versus shared leadership as predictors of the effectiveness of change management teams: An examination of aversive, directive, transactional, transformational, and empowering leader behaviors. Group Dynamics: Theory, Research, and Practice, 6(2), 172-197. https://doi.org/10.1037/1089-2699.6.2.172 
Podsakoff, P. M., MacKenzie, S. B., Moorman, R. H., \& Fetter, R. (1990) Transformational leader behaviors and their effects on followers' trust in leader, satisfaction, and organizational citizenship behaviors. The Leadership Quarterly, 1, 107-142. https://doi.org/10.1016/1048-9843(90) 90009-7

Serban, A., \& Roberts, A. J. B. (2016). Exploring antecedents and outcomes of shared leadership in a creative context: A mixed-methods approach. The Leadership Quarterly, 27, 181-199. https://doi.org/10.1016/j.leaqua.2016.01.009

Shamir, B. (1990). Calculations, values, and identities: The sources of collectivistic work motivation. Human Relations, 43(4), 313-332. https://doi.org/10 $.1177 / 001872679004300402$

Small, E. E. (2007). Shared leadership: A social network analysis. Doctoral dissertation, University of Tennessee, Knoxville, TN.

Wagner, J. A. (1995). Studies of individualism-collectivism: Effects on cooperation in groups. Academy of Management Journal, 38(1), 152-173. https://doi.org/ $10.5465 / 256731$

Wang, D., Waldman, D. A., \& Zhang, Z. (2014). A meta-analysis of shared leadership and team effectiveness. Journal of Applied Psychology, 99, 181-198. https://doi.org/10.1037/a0034531

Wang, L., Jiang, W., Liu, Z., \& Ma, X. (2017). Shared leadership and team effectiveness: The examination of LMX differentiation and servant leadership on the emergence and consequences of shared leadership. Human Performance, 30, 155-168. https://doi.org/10.1080/08959285.2017.1345909

Wang, X.-H., \& Howell, J. M. (2010). Exploring the dual-level effects of transformational leadership on followers. Journal of Applied Psychology, 95, 1134-1144. https://doi.org/10.1037/a0020754

Watson, W. E., Johnson, L., Kumar, K., \& Critelli, J. (1998). Process gain and process loss: Comparing interpersonal processes and performance of culturally diverse and non-diverse teams across time. The International Journal of Intercultural Relations, 22(4), 409-430. https://doi.org/10.1016/S0147-1767(98)00016-9

Wendt, H., Euwema, M. C., \& Van Emmerik, I. H. (2009). Leadership and team cohesivenessacross cultures. The Leadership Quarterly, 20(3), 358-370. https://doi.org/10.1016/j.leaqua.2009.03.005

Williams, E. A., Duray, R., \& Reddy, V. (2006). Teamwork orientation, group cohesiveness, and student learning: A study of the use of teams in online distance education. Journal of Management Education, 30(4), 592-616. https://doi.org/10.1177/1052562905276740

Wolf, T. (2006). Culture, leadership, and organizations: The GLOBE Study of 62 Societies [review]. In House, R. J., Hanges, P.J., \& Javidan, M. (Eds.), Journal of Applied Christian Leadership, 1(1), 55-71.

Wu J. B., Tsui A. S., \& Kinicki A. J. (2010). Consequences of differentiated leadership in groups. Academy of Management Journal, 53, 90-106. https://doi.org/10 .5465/amj.2010.48037079 
Van Vianen, A. E. M. (2000). Person-organization fit: The match between newcomers' and recruiters' preferences for organizational cultures. Personnel Psychology, 53, 1-32. https://doi.org/10.1111/j.1744-6570.2000.tb00196.x

Van Knippenberg, D., \& Sitkin, S. B. (2013). A critical assessment of charismatic: Transformational leadership research: Back to the drawing board? The Academy of Management Annals, 7, 1-60. https://doi.org/10.1080/19416520.2013.759433

Vo, A. N. (2009). The transformation of human resource management and labour relations in Vietnam. Oxford: Chandos. https://doi.org/10.1533/9781780632544

Yukl, G. (2002). Leadership in organizations (5th ed.). Upper Saddle River, NJ: Prentice-Hall. https://doi.org/10.1177/107179190200900102

Zhao, X., Lynch, J. G., \& Chen, Q. (2010). Reconsidering Baron and Kenny: Myths and truths about mediation analysis. Journal of Consumer Research, 37(2), 197-206. https://doi.org/10.1086/651257 


\section{APPENDIX}

Transformational leadership [adapted from Bass \& Avolio (1990)]

1. My leader talks about his/her most important values and beliefs.

2. My leader considers the moral and ethical consequences of decisions.

3. My leader emphasises the importance of having a collective sense of mission.

4. My leader seeks differing perspectives when solving problems.

5. My leader gets his/her to look at problems from many different angles.

6. My leader suggests new ways of looking at how to complete assignments.

7. My leader talks enthusiastically about what needs to be accomplished.

8. My leader articulates a compelling vision of the future.

9. My leader expresses confidence that goals will be achieved.

10. My leader treats me as individuals rather than just as a member of a group.

11. My leader considers an individual as having different needs, abilities, and aspirations from others.

12. My leader helps me to develop my strengths.

Shared leadership [adapted from Small (2007)]

1. High team performance is the most likely to occur when a single person is in charge. (R)

2. It would be chaotic if multiple people took on leadership responsibilities of a team. (R)

3. A team's performance will be at risk if everyone participates in the leadership role. (R)

4. To ensure that a team will be effective, the leadership role should rotate among team members.

5. A team will run more smoothly if only one person is in charge of important team decisions. (R)

6. It would be unwise for a team to make single person accountable for the team's performance.

7. It is effective to have one person in charge of a team. (R)

8. Team productivity will suffer if all team members are involved in the leadership responsibilities. ( $\mathrm{R}$ )

9. It is usually best for a team to appoint the most capable person as the leader. (R)

10. A team is vulnerable when everyone takes responsibility for leading the team. (R)

11. Putting a single person in control detracts from a team's potential to succeed.

12. A team is most productive when everyone contributes something to leading the team.

13. It is beneficial to utilise every team member's leadership capabilities to the fullest. 
Teamwork orientation [adapted from Mustafa et al. (2017)]

1. The basic idea of the team concept is good.

2. Teams are essential for effective student learning.

3. I feel positive about working in a team.

4. Teams are good for effective group functioning.

5. Teamwork is good for employees.

6. The team concept helps employees.

Team performance [adapted from Aubé \& Rousseau (2005)]

1. The members of this team attain their assigned performance goals.

2. The members of this team produce quality work.

3. This team is productive.

Quality of group experience [adapted from Aubé \& Rousseau (2005)]

1. The social climate in our work team is good.

2. In our team, relationships are harmonious.

3. In our team, we get along with each other.

Team viability [adapted from Aubé \& Rousseau (2005)]

1. Team members adjust to the changes that happen in their work environment.

2. When a problem occurs, the members of this team manage to solve it.

3. The new members are easily integrated into this team.

4. The members of this team could work a long time together. 